\title{
Pengaruh Kompres Dingin dalam Penurunan Nyeri Pasien Post Percutaneous Coronary Intervention (PCI): Literature review
}

\author{
Andy Kristiyan ${ }^{1, *}$, Hery Djagat Purnomo², Chandra Bagus Ropyanto ${ }^{3}$ \\ ${ }^{1}$ Rumah Sakit Umum Pusat Dr. Kariadi, Semarang, Indonesia \\ ${ }^{2}$ Fakultas Kedokteran Universitas Diponegoro, Semarang, Indonesia \\ ${ }^{3}$ Departemen Ilmu Keperawatan Fakultas Kedokteran Universitas Diponegoro, Semarang, Indonesia \\ andy_cardio@yahoo.com
}

\begin{abstract}
Introduction: Complications in catheterization vascular access range from 1\%-61\%. One of interventions that can be taken to prevent hematoma and reduce pain in post PCI patients at off sheath is with cold compresses or ice bag. The fact shows that pain and hematoma in patient PCI in hospital just done by using sand bag therapy. There was a limited review about the use of ice bag to reduce pain in patients with $P C I$.

Methods: Searched articles through Science Direct, PubMed, EBSCO and Google Scholar conducted using advanced searching with keywords including "ice bag", "pain", and "percutaneous coronary intervention". Searching through Google Scholar using keywords involving "effectiveness of ice bag on pain in patient's percutaneous coronary intervention (PCI)".

Results: There were three articles control trials and the results showed that implementation of cold compresses with ice bag for 20 minutes before and after catheter release in PCI measures was significant in reducing pain $(P<0.05)$.

Conclusion: Giving cold compresses can reduce pain because it can inhibit the fibber of smalldiameter nerves in delivering pain stimuli.
\end{abstract}

Keywords: Ice bag, Pain, Percutaneous coronary intervention

\begin{abstract}
Abstrak
Pendahuluan: Komplikasi pada akses pembuluh darah kateterisasi berkisar antara 1\% - 61\%. Salah satu tindakan yang dapat dilakukan untuk mencegah hematoma dan mengurangi nyeri pada pasien post PCI pada saat off sheath adalah dengan kompres dingin. Fakta memperlihatkan nyeri dan hematom pada pasien post PCI di rumah sakit hanya diatasi dengan pemberian terapi bantal pasir. Belum terdapat telaah artikel terkait penggunaan kompres dingin dengan ice bag untuk mengurangi nyeri pada pasien PCI.

Metode: Artikel dicari melalui Science Direct, PubMed, EBSCO dan Google Scholar menggunakan advanced search dengan kata kunci "ice bag", "pain", dan "percutaneous coronary intervention". Pencarian melalui google scholar dengan kata kunci "effectiveness ice bag on pain in patient's percutaneous coronary intervention (PCI)".

Hasil: Telaah tiga artikel control trialsl menunjukkan bahwa pelaksanaan kompres dingin selama 20 menit sebelum dan setelah pelepasan kateter pada tindakan PCI signifikan dalam menurunkan nyeri ( $p$ $<0,05)$.
\end{abstract}


Kesimpulan: Pemberian kompres dingin dapat menurunkan nyeri karena dapat menghambat perjalanan saraf berdiameter kecil dalam menghantarkan rangsang nyeri.

Kata kunci: Ice Bag, Nyeri, Percutaneous coronary intervention

\section{PENDAHULUAN}

Coronary Artery Disease (CAD) merupakan suatu keadaan dari adanya arterosklerosis dan thrombosis (arterothrombosis), dan ini sering menjadi penyebab kematian dan angka kesakitan di banyak negara industri di dunia (Shah, 2006). Tindakan perkutan yang dilakukan pada klien CAD adalah angiografi koroner dan Percutaneous Coronary Intervention (PCI) (Woods, Fruelicher, Motzer, \& Bridges, 2005). Komplikasi dapat terjadi pada tindakan angiografi koroner yang dibagi menjadi komplikasi mayor dan minor. Menurut the Pennsylvania Patient Safety Reporting System (PA-PSRS) Patient Safety Advisory, komplikasi tersebut antara lain komplikasi pembuluh darah akses kateter, aritmia, transient ischemic attack, gangguan fungsi ginjal, infeksi, dan komplikasi minor. Komplikasi pada akses kateter ke pembuluh darah antara lain perdarahan, hematom, perdarahan retroperineal, dan pseudoneurisma (PA-PSRS Patient Safety Advisory, 2007).

Berdasarkan data the American Collage of Cardiologist Benchmark tahun 2007 insiden komplikasi tindakan angiografi koroner tidak lebih dari $1 \%$ pada prosedur tindakan diagnostik dan 3\% prosedur tindakan intervensi. Komplikasi pada akses pembuluh darah kateterisasi berkisar antara 1\%-61\% yang dipengaruhi oleh jenis prosedur, terapi antikoagulan, penggunaan alat penutup pembuluh darah, umur dan jenis kelamin (PA-PSRS Pasient Safety Advisory, 2007).

Salah satu tindakan yang dapat dilakukan untuk mencegah hematoma dan mengurangi nyeri pada pasien post PCI pada saat off sheath adalah dengan kompres dingin (Bayindir, Gülsüm, \& Abdurrahman, 2017).

Fakta memperlihatkan nyeri dan hematom pada pasien post PCI di rumah sakit hanya diatasi dengan pemberian terapi bantal pasir. Telaah artikel terkait penggunaan kompres dingin dengan ice bag untuk mengurangi nyeri pada pasien PCI belum ditemukan sangat terbatas. Telaah yang ditemukan terkait pemberian ice bag untuk mengurangi nyeri pada pasien yang dilakukan penusukan di arteri (Bastami, Armand, \& Masoud, 2015). Telaah artikel sangat penting dilakukan telaah artikel untuk mengetahui pengaruh penggunaan ice bag dalam menurunkan nyeri pasien PCI yang akan dilakukan pelepasan shent.

\section{METODE}

Pencarian melalui Sciencedirect, PubMed, dan EBSCO dilakukan menggunakan advanced search dengan kata kunci "ice bag", "pain", dan "percutaneous coronary intervention". Pencarian melalui google scholar dengan kata kunci "effectiveness ice bag on pain inpatients percutaneous coronary intervention (PCI)". Didapatkan tiga artikel dengan sebuah Randomized Control Trials (RCTs) dan dua artikel dengan desain penelitian control trial.

Kriteria inklusi yaitu studi primer berupa RCTs dan Non Randomized Control Trials atau Control Trials, full 
text, dan dalam bahasa Inggris. Subjek dalam artikel menjalani prosedur PCI atau prosedur kateterisasi. Intervensi yang digunakan merupakan terapi kompres dingin dengan ice bag. Outcome artikel harus mengukur tingkat nyeri responden setelah dilakukan intervensi, outcome sekundernya adalah mengukur kejadian hematom. Pencarian dibatasi pada tahun 2009-2019. Pencarian literatur bisa dilihat pada Tabel 1. Proses pencarian literatur

Tabel 1. Proses pencarian literatur

\begin{tabular}{|c|c|c|c|c|c|}
\hline 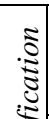 & $\begin{array}{l}\text { Science } \\
\text { direct }\end{array}$ & $\begin{array}{l}\text { Pub- } \\
\text { Med }\end{array}$ & $\begin{array}{l}\text { EBSC } \\
\mathrm{O}\end{array}$ & $\begin{array}{l}\text { Google } \\
\text { Schola } \\
\mathrm{r}\end{array}$ & \\
\hline בే & $\mathrm{N}=424$ & $\begin{array}{l}\mathrm{N}= \\
183\end{array}$ & $\begin{array}{l}N= \\
212\end{array}$ & $\begin{array}{l}N= \\
304\end{array}$ & \\
\hline \multirow{4}{*}{ 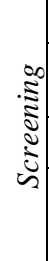 } & \multicolumn{4}{|c|}{ Judul } & \\
\hline & $\mathrm{N}=2$ & $\begin{array}{c}\mathrm{N}= \\
3\end{array}$ & $\mathrm{~N}=3$ & $\mathrm{~N}=1$ & \\
\hline & \multicolumn{4}{|c|}{ Judul yang sama } & \multirow{2}{*}{$\begin{array}{l}\text { Judul } \\
\text { yang } \\
\text { sama }(\mathrm{N} \\
=) 2\end{array}$} \\
\hline & & & $=2$ & & \\
\hline \multirow{2}{*}{ 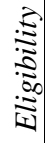 } & \multicolumn{4}{|c|}{ Artikel full text } & \multirow{2}{*}{$\begin{array}{l}\text { Hanya } \\
\text { abstrak } \\
(\mathrm{N}=0)\end{array}$} \\
\hline & \multicolumn{4}{|c|}{$\mathrm{N}=7$} & \\
\hline \multirow[b]{2}{*}{ 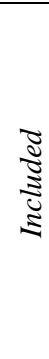 } & \multicolumn{4}{|c|}{$\begin{array}{c}\text { Setelah dilakukan pembacaan } \\
\text { yang disesuaikan dengan kriteria } \\
\text { inklusi }\end{array}$} & $\begin{array}{l}\text { Tidak } \\
\text { sesuai } \\
\text { inklusi }\end{array}$ \\
\hline & \multicolumn{4}{|c|}{$\mathrm{N}=3$} & $\begin{array}{l}(\mathrm{N}=4), \\
\text { Bukan } \\
\text { Pasien } \\
\text { PCI atau } \\
\text { katerisas } \\
\text { i jantung } \\
=4\end{array}$ \\
\hline
\end{tabular}

\section{HASIL}

Setelah dilakukan pencarian literatur sesuai batasan karakteristik terdapat tiga artikel yang dipilih. Sebuah artikel menggunakan metode RCTs (Randomized Control Trials) dan dua artikel menggunakan metode control trial. Artikel yang didapat menunjukkan bahwa penerapan ice bag pada saat sebelum dan setelah pelepasan stent PCI ataupun kateterisasi jantung dapat menurunkan nyeri yang dialami pasien (Bayindir, Gülsüm, \& Abdurrahman, 2017); Çürük, Taşc1, Elmalı, \& Oghuzan, 2017; Ibraheem, 2016). Proses ekstraksi data dapat dilihat pada tabel ekstraksi data (tabel 2).

\section{PEMBAHASAN}

Bayindir, Gülsüm, dan Abdurrahman (2017) menunjukkan bahwa pemberian kompres dingin dengan ice bag dapat menurunkan nyeri pasien yang dilakukan PCI. Nyeri saat dan setelah pelepasan kateter berkurangan setelah pemberian kompres selama 20 menit sebelum kateter dilepas. Selain itu Bayindir et al. juga menyebutkan bahwa komplikasi yang terjadi setelah pelepasan kateter pada kelompok intervensi tidak terjadi. Çürük, Taşc1, Elmalı, \& Oghuzan (2017) menunjukkan bahwa nyeri pada pasien mengalami penurunan setelah dilakukan kompres dingin. Ibraheem (2016) menunjukkan bahwa nyeri setelah pelepasan kateter berkurang setelah diberikan kompres dua puluh menit sebelum pelepasan dan dua puluh menit setelah pelepasan.

Pemberian kompres dingin dapat menurunkan nyeri karena dapat menghambat perjalanan saraf berdiameter kecil dalam menghantarkan rangsang nyeri. Sehingga stimulus dari perifer tidak bisa dihantarkan ke sistem saraf pusat (Demir, 2012). Nyeri pada pasien PCI dapat meningkatan kejadian vasovagal atau komplikasi vaskular lain, sehingga nyeri pasien harus segera diatasi. Reaksi vasovagal yang tidak diatasi akan menyebabkan terjadinya syok yang irreversible dan akhirnya menyebabkan kematian. Nyeri juga dapat menyebabkan cemas pasien sehingga akan memperlama 
Tabel 2. Ekstraksi data

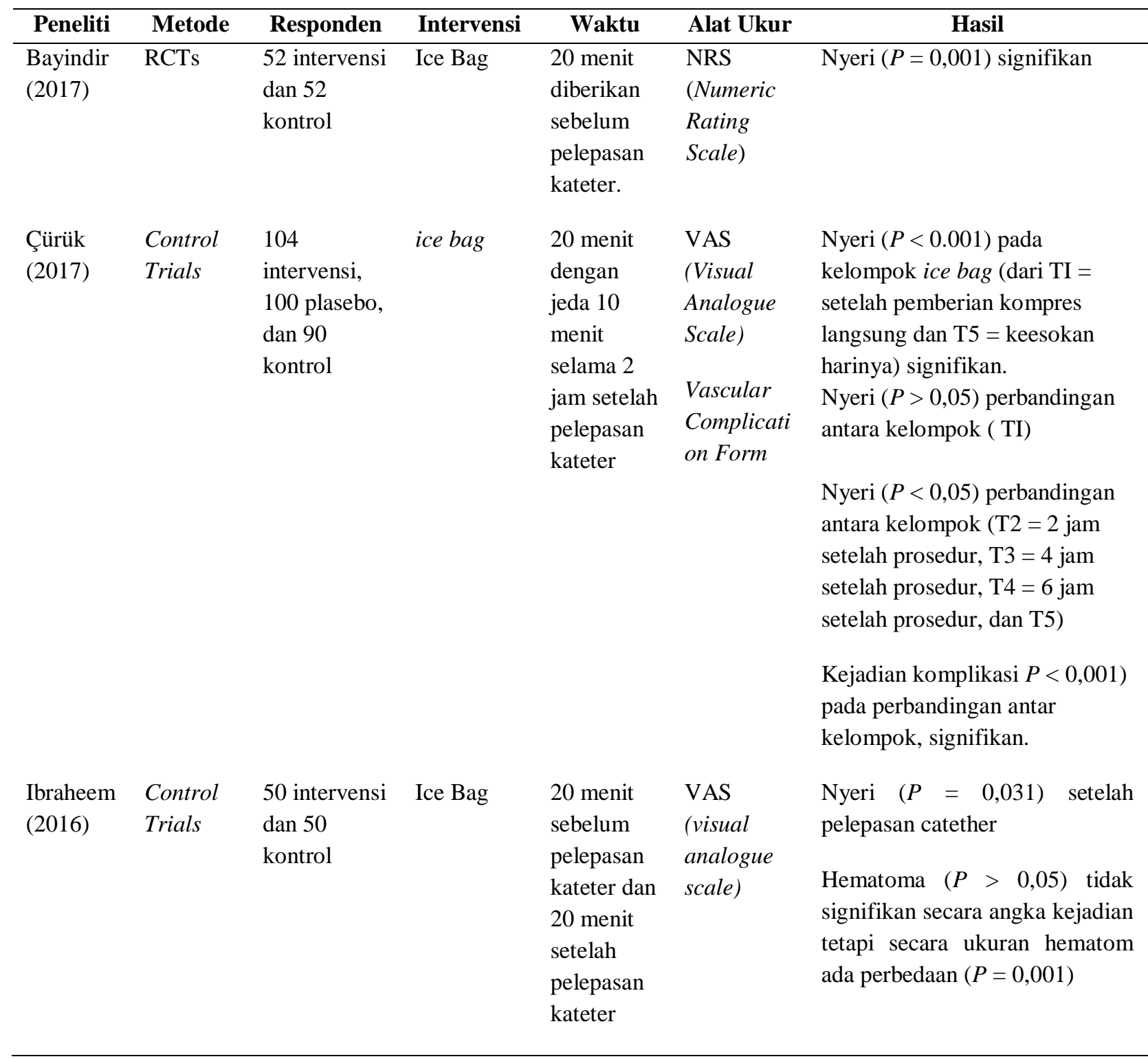

proses perawatan pasien dan pada akhirnya akan meningkatkan biaya perawatan pasien (Bayindir, Gülsüm, \& Abdurrahman, 2017).

Beberapa literatur yang ada menyatakan bahwa es dapat meredakan nyeri secara efektif. Es telah digunakan di dalam maupun di luar rumah sakit dalam kontrol nyeri yang terkait dengan bedah dan trauma. Penerapannya sebagai penghilang rasa sakit diterima secara luas, meskipun mekanisme es mencapai penghilang rasa sakit tidak jelas. Beberapa penjelasan penggunaan es sebagai analgesia memang ada, tetapi tidak pasti dan tidak terbatas pada: penurunan transmisi rasa sakit melalui saraf, penurunan peradangan dan peningkatan ambang nyeri, dan sensasi dingin mengalahkan sensasi rasa sakit. Teori yang 
dikemukakan tersebut mengarah pada teori gate control (Wentwoth et al., 2013). Dari beberapa teori yang ada, penurunan nyeri saat pemberian terapi ice bag mengarah pada teori gate control.

Teori gate control rasa sakit, dijelaskan es bertindak pada nosiseptor (reseptor rasa sakit) untuk menumpulkan persepsi rangsangan mekanik dan kimia lainnya, termasuk rasa sakit, dengan menutup "gerbang" sensasi ke sistem saraf pusat. Sesuai dengan teori ini, es yang dioleskan langsung ke tempat rangsangan nyeri dapat mengurangi rasa sakit. Penelitian lain menyebutkan bahwa es dapat bekerja di sistem saraf perifer dengan mengurangi kecepatan transmisi di saraf dan dengan demikian meningkatkan ambang nyeri dan toleransi nyeri di sepanjang saraf yang sama. Ada sumber yang menyatakan bahwa aplikasi es, bersama dengan intervensi farmakologis dapat mengurangi efek samping, meningkatkan hasil, dan mengurangi masa rawat di rumah sakit. Terapi es dapat mengurangi kebutuhan dosis opioid atau narkotika, sehingga mengurangi potensi komplikasi obat. Penggunaan aplikasi es bersama dengan penggunaan agen farmakologis dapat digunakan secara efektif untuk mengurangi rasa nyeri.

Aplikasi kompres dingin untuk pengobatan nyeri akut dan kronis dianggap sebagai intervensi keperawatan nonfarmakologis (Wentwoth et al., 2013). Tujuan akhir dari terapi non farmakologi adalah membuat pasien mejadi nyaman, penurunan rasa takut, mengurangi stress dan nyeri (Wente, 2013). Aplikasi ice bag merupakan suatu tindakan keperawatan yang sederhana, mudah, murah, dan noninvasif yang harus dilakukan karena pengaruhnya besar terhadap kenyamanan pasien (Bastami, Armand, \& Masoud, 2015).
Kompres dingin dapat menurunkan aliran darah dan permeabilitas kapiler di sekitar tempat penusukan. Selain itu kompres dingin juga dapat menyebabkan terjadinya vasokonstriksi pembuluh darah. Mekanisme kerja tersebut dapat mengontrol perdarahan dan memfasilitasi koagualasi dengan cara meningkatkan viskositas darah. Kondisi tersebut mengakibatkan perdarahan, hematoma, dan ekimosis lebih sedikit terjadi atau bahkan tidak terjadi saat dilakukan kompres dingin pada jaringan (Çürük, Taşcı, Elmalı, \& Oghuzan, 2017; King, Philpott, \& Leary, 2008). Penurunan suhu pada jaringan kulit akan menyebabkan peningkatan vasokonstriksi pembuluh darah (King, Philpott, \& Leary, 2008). Cold pack dengan ambulasi dini lebih baik digunakan dari pada bantal pasir dalam mengurangi kejadian hematoma pada pasien yang dilakukan kateterisasi jantung (Ginanjar, Hadisaputro, Mardiyono, \& Sudirman, 2018).

\section{KESIMPULAN DAN SARAN}

Penggunan kompres dingin dengan ice bag dapat menurunkan nyeri pada pasien dengan PCI saat dan setelah pelepasan kateter. Perlu adanya implementasi pada pelayanan kesehatan dalam penurunan nyeri dan komplikasi PCI.

\section{DAFTAR PUSTAKA}

Bastami, M., Arman, A., \& Masoud M. (2015). The use of ice pack for pain associated with arterial punctures. Journal of Clinical and Diagnostic Research, 9(8), 7-9.

Bayindir, S. L., Gülsüm, N. C., \& Abdurrahman, O. (2017). Effect of ice bag application to femoral region on pain in patients undergoing 
percutaneous coronary intervention. Pain Research and Management, 17. doi: $10.1155 / 2017 / 6594782$

Çürük, G. N., Taşcı, S., Elmalı, F., \& Oghuzan, A. (2017). The effect of ice-bag applied to femoral region of individuals with percutaneous coronary intervention on local vascular complications and low back-pain. IOSR Journal of Nursing and Health Science, 6(1), 136-144. doi: 10.9790/1959-060105136144

Demir. Y. (2012). Pain and management, in Fundamentals of Nursing. Turkey, Istanbul: Akademi of Broadcasting, 626-659.

Ginanjar, R., Hadisaputro, S., Mardiyono, \& Sudirman. (2018). Effectiveness of cold pack with early ambulation in preventing complications of haemorrhage and haematoma in patients post cardiac catheterization. Belitung Nursing Journal, 3(1), 8388.

Ibraheem, S.E. (2016). The effectiveness of using ice application on vascular access site complication after cardiac catheterization. IOSR Journal of Nursing and Health Science, 5(1), 08-16. doi: 10.9790/1959-05140816

King, N. A., Philpott, S. J., \& Leary, A. (2008). A randomized controlled trial assessing the use of compression versus vasoconstriction in the treatment of femoral hematoma occuring after percutaneous coronary intervention. Heart \& Lung, 37(3), 205-210.

doi:

10.1016/j.hrtlng.2007.05.008

PA-PSRS Patient Safety Advisory. (2007). Strategies to minimize vascular complications following a cardiac catheterization. Article PA-PSRS Patient safety advisory. 45 (4), 2024.

Shah, P.K (Ed). (2006). Risk Factor in Coronary Artery Disease. London: Taylor \& Francis Group.

Wente, S. J. K. (2013) Nonpharmacological pediatric pain management in emergency departments: A systematic review of the literature. Journal of Emergency Nursing, 39(2), 140-150. Doi: 10.1016/j.jen.2012.09.011

Wentworth, L.J. Bechtum, E. L., Hejlik, J. B., Scott, C. G., Munger, T. M., Brady, P.A.,...Bridley, J. K. (2013). A pilot study: Effects of ice therapy on vascular access site pain following atrial fibrillation radiofrequency catheter ablation. $E P$ Lab Digest, 13(2), 1-13.

Woods, S.1., Fruelicher, E.S., Motzer, S.U., Bridges, E.J. (2005). Cardiac Nursing. 5ed. Philadelphia: Lippincott. 